\title{
Impact of MTDC grid reconfiguration and control on the dynamics of the GB System
}

\section{Document Version}

Accepted author manuscript

Link to publication record in Manchester Research Explorer

\section{Citation for published version (APA):}

Shah, R., Barnes, M., \& Preece, R. (2019). Impact of MTDC grid reconfiguration and control on the dynamics of the GB System. Paper presented at IET AC/DC Conference, Coventry, United Kingdom.

\section{Citing this paper}

Please note that where the full-text provided on Manchester Research Explorer is the Author Accepted Manuscript or Proof version this may differ from the final Published version. If citing, it is advised that you check and use the publisher's definitive version.

\section{General rights}

Copyright and moral rights for the publications made accessible in the Research Explorer are retained by the authors and/or other copyright owners and it is a condition of accessing publications that users recognise and abide by the legal requirements associated with these rights.

\section{Takedown policy}

If you believe that this document breaches copyright please refer to the University of Manchester's Takedown Procedures [http://man.ac.uk/04Y6Bo] or contact uml.scholarlycommunications@manchester.ac.uk providing relevant details, so we can investigate your claim.

\section{OPEN ACCESS}




\title{
Impact of MTDC Grid Reconfiguration and Control on the Dynamics of the GB System
}

\author{
Rakibuzzaman Shah $^{1,2 *}$, Robin Preece ${ }^{1}$, Mike Barnes ${ }^{1}$ \\ ${ }^{1}$ School of Electrical and Electronic Engineering, The University of Manchester, M13 9PL, UK \\ ${ }^{2}$ School of Engineering and Technology, CQUniversity, Perth, WA 6000, Australia \\ *email: rakibuzzaman.shah@manchester.ac.uk
}

Keywords: Dynamics, MTDC grid, power flow solver, pilot voltage droop, reconfiguration, stability.

\begin{abstract}
Multi-terminal DC (MTDC) grids are becoming increasingly popular for interconnecting non-synchronous generating resources such as offshore wind power plants (WPPs). The benefit of MTDC systems is that they can be reconfigured during contingencies to maintain the supply of power to the host AC systems. DC grid reconfiguration in MTDC systems will inevitably change the power injections to the host $\mathrm{AC}$ system, and will thus affect the dynamic behaviour of the AC system. This paper investigates the dynamic behaviour of the representative Great British (GB) transmission system (i.e. a reduced order dynamic model) for a series of reconfigurations in a meshed MTDC grid connecting offshore WPPs to the system. Hierarchical control strategies for the MTDC system including a DC power flow solver (PFS) and pilot voltage droop (PVD) are compared. From the analysis, it is observed that the reconfiguration of MTDC grid has a notable impact on large-disturbance dynamics of the GB transmission system.
\end{abstract}

\section{Introduction}

Due to the rising number of offshore wind power plants (WPPs) far from the shore, and the growing desire for increased interconnection between different asynchronous zones to enable cross-border trading and improve security, HVDC technology will play a significant role in future power systems [1]. According to the European Network of Transmission System Operators for Electricity (ENTSO-E), approximately a quarter of the required upgrades in transmission systems over the next ten years will be realized using HVDC systems [2]. Therefore, many power systems will feature a combination of AC and HVDC transmission in future. The point-to-point HVDC technology based on the classical, line commutated converter (LCC), is well established for bulk power transmission. However, the appearance and rapid development of voltage source converter (VSC) technology has enabled the use of VSC-HVDC systems for HVDC links due to its advantages over LCCHVDC technology. Most of the existing VSC-HVDC links are point-to-point, except the Chinese Nan'ao Island and Zhoushan HVDC systems, which are multi-terminal (MT)HVDC systems, or simply MTDC systems [3], [4]. It should be noted that both systems are of the radial type. A fully meshed MTDC grid is yet to be constructed and tested.
Indeed to have a secure energy supply with higher reliability, MTDC is widely considered a necessary development. It is envisaged that many of the existing and planned point-topoint HVDC links will become interconnected on their DC sides in the future to form an MTDC system [5]. There are several challenges related to the development and operation of MTDC grids including grid structure, converter control strategy for multivendor converters, and DC voltage stability among others. Several methods have been reported to deal with the DC voltage stability in MTDC systems [5], [6]. The dynamic behaviour of the MTDC grid is analysed and reported in [7]. The adaptive scheme of droop control strategy and the impacts of the autonomous control during transient events are reported in [8]. The dynamic interaction between the Modular Multilevel Converter (MMC) based MTDC grid and AC system is presented in [9] with a DC voltage droop to maintain the voltage stability of the DC system. The VSC-HVDC system control parameters and their impacts on the stability of the AC system in the electromechanical time-frame are discussed in [10].

The concept of hierarchical control for an MTDC grid is outlined in [5], [11], and [12]. Studies in [5] presented hierarchical DC grid control by extrapolating the strategies used in control and operation of AC grids. The control operation during standard and outage cases is assessed and reported in [5]. The use of an optimal power flow (OPF) based secondary control and droop based primary control is proposed in [13]. The OPF based secondary controller has been used as a supplementary controller to adjust the reference points of the primary droop controllers. A similar idea has been proposed in [14], and the performances are assessed for various droop characteristics and converter outage cases with simple AC systems.

A great deal of excellent research on MTDC grid operation has been undertaken including studies to investigate the influence of various MTDC primary controllers on DC power flow and AC system dynamics [15], but it is yet to be fully established as to how MTDC grid reconfiguration and various hierarchical controllers will affect AC system dynamics. From the AC system perspective, DC grid reconfiguration (i.e. extended outage of DC grid converters and lines) could lead to temporary or permanent power imbalances and the loss of AC system voltage support to the host AC grids. The fast-changing power transfer at different 
terminals could also excite poorly damped modes in the connected AC grids, resulting in significant rotor-angle deviations in generators located electrically distant [16] thus affecting the stability of the system. Therefore, this work aims to analyze the impact of MTDC grid reconfiguration on the host AC system (in this case a representative GB transmission system) rotor angle and frequency stability for various operating scenarios.

This paper will continue as follows. Firstly, an overview of the MTDC control including the AC-DC system modelling will be discussed. Then, the AC-DC system stability for various hierarchical controls and operating conditions will be assessed under DC grid reconfiguration. Finally, the paper ends with conclusions and future research directions.

\section{MTDC grid control}

This section will outline the MTDC grid control schemes necessary to enable reconfigurability during DC outage contingencies. Full details of standard controls for VSCHVDC are not discussed in detail but can be found in [9][15].

\subsection{Droop control}

The stability and reliability of an MTDC system can be enhanced by employing multiple converters for DC voltage control. Therefore, DC voltage droop has been reported as the favorable option for DC voltage control. Several droop control schemes have been reported and are further categorized in a simple framework in [17]. The control structure for droop control can principally be classified into two:

a) Voltage-current (AC and DC).

b) Voltage-power (AC and DC).

Based on the experience of $\mathrm{AC}$ system operation with frequency control, a voltage-power droop scheme is the preferred droop control for MTDC system [15], [17], as shown in Fig. 1. When the converter is under droop control scheme, the below constraint is followed by the converter:

$$
P=k\left(V_{D C}-V_{D C r e f}\right)+P_{r e f}
$$

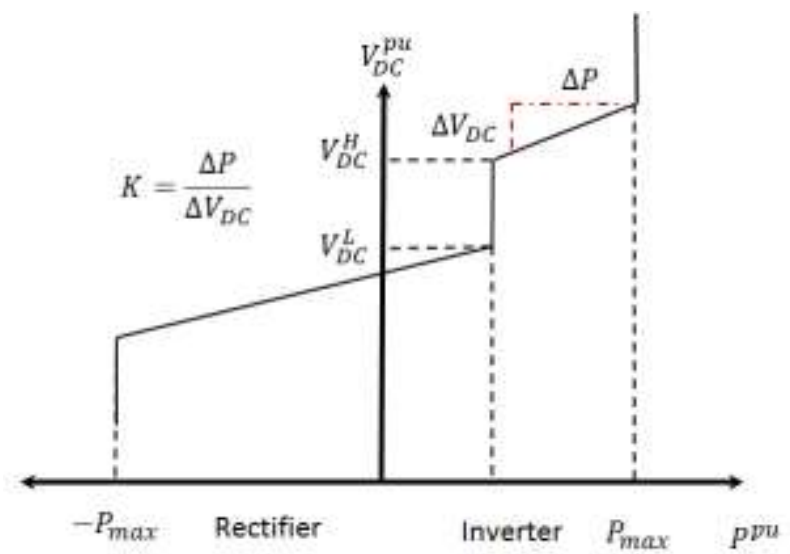

Fig. 1: Steady-state characteristics of voltage-power droop.
Dead-band based control is used in the droop controller (see Fig. 1) to avoid active power changes due to a small perturbation of DC voltage. The concept of dead-band based droop control is that a converter with dead-band control will operate in a constant power/current mode under typical conditions and will only participate in voltage control when the voltage thresholds are violated (the typical voltage threshold range for the dead-band droop is 1.015-0.975 pu [15]).

\subsection{Pilot voltage droop control}

Pilot voltage droop control utilizes a communication channel to transfer the measured value of DC link voltage (measured at any arbitrary station) to the pilot bus droop controller. The pilot bus droop controller defines the relationship between DC voltage regulation and power changes in the MTDC grid. Fig. 2 shows the schematic diagram of the pilot bus droop controller method for MTDC systems. As seen from Fig. 2, the DC voltage at all converter stations (irrespective to the converter control) are communicated to the centralized controller, and the average DC link voltage is obtained as (2) [18]:

$$
V_{\text {DCavg }}=\sum_{i=1}^{n} \frac{V_{D C i}}{n}
$$

In (2), $V_{D C i}$ is the voltage at the $i^{\text {th }}$ converter, $n$ is the total number of converters in the MTDC system. The difference of the nominal voltage and the average voltage is then fed to the centralized PI controller to produce the voltage shifting signal $\left(\Delta V_{\text {avg }}\right)$. This voltage shifting term is then added to the DC voltage reference term of all the converters in the MTDC grid.

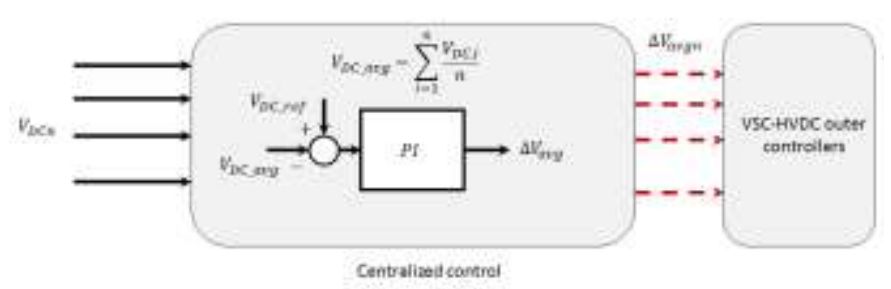

Fig. 2: Control diagram of pilot bus droop control [18].

\subsection{Power flow solver}

The optimal power flow (OPF) solver has widely been proposed in the literature as a hierarchical secondary control layer for MTDC systems [12]-[14],[19]. A hierarchical control algorithm referred to as a Power Flow Solver (PFS) is proposed and analyzed in [14]. A basic control block diagram of MTDC system with PFS is given in Fig. 3. The main function of the PFS is to ensure the stable operation of the HVDC system in the presence of power injection and demand mismatch in the MTDC grid. This is accomplished by updating the local droop control set points. The centralized PFS as shown in Fig. 3 estimates the droop set points for the converters in the MTDC grid (these set points could be DC voltage, power and current) corresponding to the measured 
MTDC data. The measured MTDC data for PFS can be DC voltage and power.

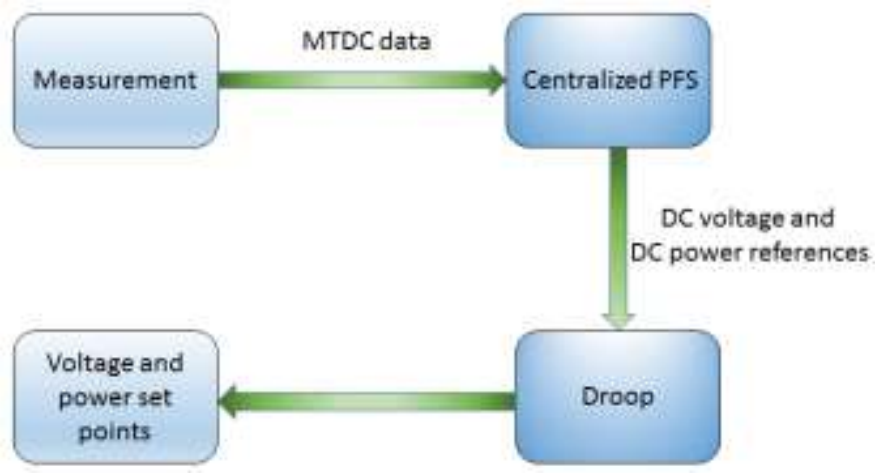

Fig. 3: Block diagram of PFS based hierarchical control [14].

For this work, a similar model to the PFS given in [14] is used to obtain the target DC voltage for each converter terminal within the system. Local controllers are used to take into consideration fast dynamics associated with converters and cables in the HVDC system. A hierarchical control algorithm such as PFS will be executed at a much slower rate than the local controllers. The PFS adapts to slow (quasisteady state) changes in the system state. For example, if a line is taken out of service, the PFS will adapt set points of local controllers to new quasi-steady state (reconfigured) operating values. Thus for faster transients, the PFS set points typically appear to be quasi-steady state unchanging values the approach taken here.

\section{Test system}

The AC system model given in Fig. 4 is a modified reduced order dynamic model of the GB transmission network. The model is developed based on reference load flow cases [10]. Dynamic data is included to enable stability analysis of the system. This includes detailed generator models $\left(6^{\text {th }}\right.$ order model), excitation systems (IEEE DC1A), power system stabilizers, and generic governor system models. The resulting dynamic model has a total generation capacity of 75 $\mathrm{GW}$ with a peak load demand of $60 \mathrm{GW}$. The power is mainly transmitted from Scotland (North) to England-Wales (South). The full details about the model and parameters can be found in [10] and the references therein.

The five terminal offshore MTDC system shown in Fig. 5 is used for this study. Two aggregated offshore WPPs of 2000 MW each are considered in this work to represent some of the offshore wind power development anticipated around the UK. The WPPs are integrated to the onshore AC system by the meshed MTDC system shown in Fig. 5. Each converter terminal in the system is rated at $2000 \mathrm{MW}, \pm 500 \mathrm{kV}$. A DC chopper is included at the onshore converters to facilitate AC system fault-ride through. The onshore terminals of the MTDC system are connected at bus 7, 10, and 15 in the GB system given in Fig. 4. It should be noted that the generators at bus $1,2,3$, and 4 are decommissioned to facilitate the offshore MTDC system into the GB system. The AC-DC grid is modelled in DIgSILENT Power Factory 17.0 [20]. The detailed parameters of WPPs can be found in [21] and the references therein. The parameters related to VSC-MTDC system are given in the Appendix.

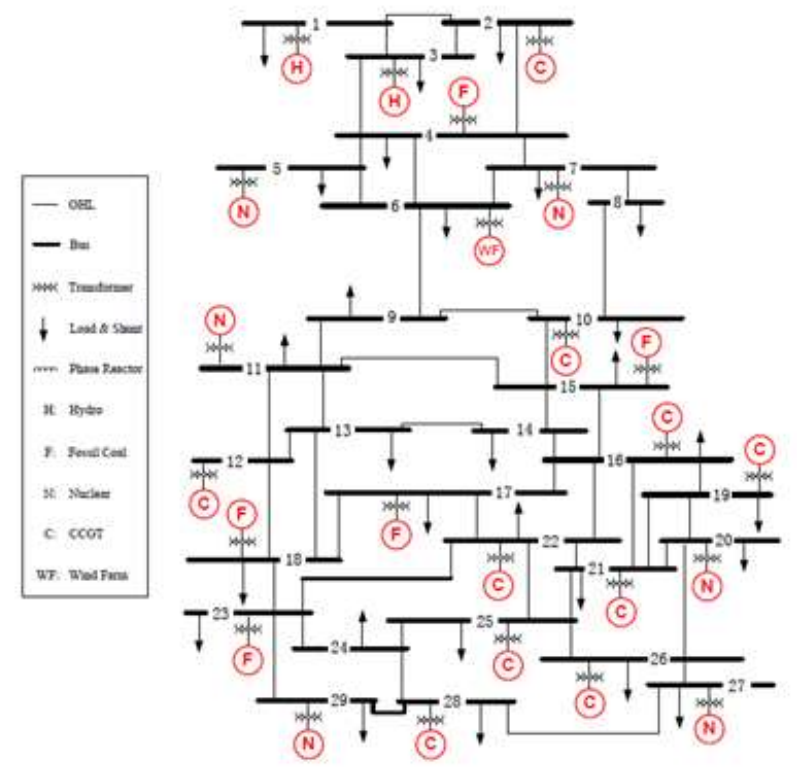

Fig. 4: Representative GB transmission system [11].

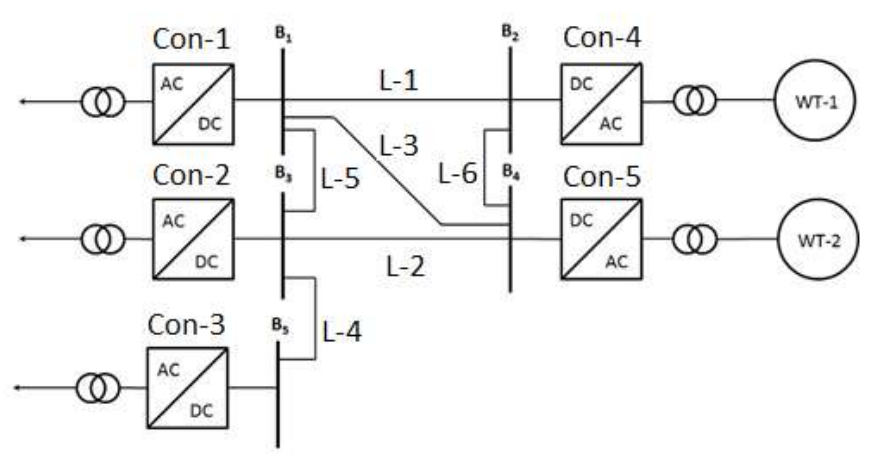

Fig. 5: Schematic diagram of MTDC system.

\section{Numerical study}

\subsection{Stability indices}

From the perspective of AC-side small-disturbance rotor angle stability, the investigation focuses on the impact of the MTDC grid reconfiguration on the damping of the critical interarea mode of the system. The QR analysis method [20] has been used to evaluate the eigenvalues within the frequency range of interest (i.e. $0.2-1.0 \mathrm{~Hz}$ ), and the corresponding damping ratios (\% damping) are calculated and reported. The largedisturbance rotor angle stability of the host AC system is assessed in this work by the transient stability index (TSI) presented in [21]. The TSI is given as (3) [21]:

$$
T S I=\frac{360^{\circ}-\delta_{M A X}}{360^{\circ}+\delta_{M A X}}
$$

In (3), $\delta_{M A X}$ is the maximum rotor angle separation between two synchronous generators at any instant in time. 
In this study, $\delta_{\mathrm{MAX}} \delta_{\text {MAX }}$ of any $i^{\text {th }}$ generator is evaluated concerning the reference machine rotor angle $\left(\delta_{\text {ref }}\right)\left(\delta_{\text {ref }}\right)$, as in (4) [21]:

$$
\delta_{M A X}=\delta_{i}-\delta_{r e f}
$$

The Rate of Change of Frequency (RoCoF) [22] is employed here to assess the frequency stability of the system. The practical aspects of $\mathrm{RoCoF}$ measurement include the determination of time window over which RoCoF is calculated. Different time windows will result in different values of RoCoF. The RoCoF values are calculated numerically using a $500 \mathrm{~ms}$ measurement window as reported in [22].

\subsection{Operating scenarios}

Dynamic analysis has been carried out in this section for various operating conditions such as loading levels, MTDC system reconfiguration, and DC link power flow. Three AC system loading conditions, i.e. light, medium, and heavy loading are used for the analysis. The following reconfigurations of the MTDC system given in Table 1 are used in this work. The MTDC grid reconfiguration scenarios presented in Table 1 are evaluated for the DC link power flows given in Table 2 to estimate the effect of MTDC grid reconfiguration on the dynamic behaviour of the host $\mathrm{AC}$ system. In each outage (apart from base case), outages have taken place and the hierarchical controllers are updated local controllers to reflect the changes in Table 1. The transient conditions of DC outage are in a faster time-frame than the hierarchical controllers. Therefore, the fast dynamic responses to the updated DC system are not assessed - the simulations assume an updated quasi-steady state has been reached. It should be noted that the 'base case' is the case with hierarchical control but without the outage.

Table 1: MTDC grid operational scenarios

\begin{tabular}{|c|c|}
\hline Case & Remark \\
\hline Outage Case 1 & DC line -1 and - 3 outage \\
\hline Outage Case 2 & Converter-1, DC line-5,-3, and -1 outage \\
\hline Outage Case 3 & DC line -2 outage \\
\hline Outage Case 4 & Converter-2 outage \\
\hline Outage Case 5 & $\begin{array}{c}\text { Converter-4 outage, DC line-1 and -6 } \\
\text { outage }\end{array}$ \\
\hline Outage Case 6 & $\begin{array}{c}\text { Converter-5, DC line-2,-3, and -6 outage } \\
\text { The base case with master PFS and PVD } \\
\text { in the MTDC system }\end{array}$ \\
\hline
\end{tabular}

Table 2: DC link power from MTDC and load combinations

\begin{tabular}{|c|c|}
\hline AC system loading & DC link power $(\mathbf{M W})$ \\
\hline \multirow{2}{*}{ Light } & 2500 \\
& 2900 \\
& 3100 \\
\hline \multirow{2}{*}{ Medium } & 2500 \\
& 2900 \\
\hline \multirow{2}{*}{ Heavy } & 3100 \\
& 2500 \\
\hline & 2900 \\
\hline
\end{tabular}

\subsection{Impact on rotor angle stability}

This section investigates the impact of DC grid reconfiguration on the host AC system small-and largedisturbance rotor angle stability. Analyses are conducted for a wide range of operating conditions as given in Table 1 and 2 . The investigations are completed for both the system with and without MTDC grid reconfiguration. Table 3 shows the small-disturbance analysis results for the MTDC grid reconfiguration scenarios given in Table 1 for the heavy loading condition with total DC power flow of $3100 \mathrm{MW}$. Primarily, without an MTDC grid connected into the GB system, the system has a critical interarea mode of $f=0.48$ $\mathrm{Hz}$ and $\zeta=2.96 \%$.

The results in Table 3 show that the MTDC grid reconfiguration with hierarchical controllers has only a minimal effect on the interarea mode damping since the tieline power flow variations in the host AC system are minimal for different reconfigurations of MTDC system under the considered operating scenarios. From the results in Table 3, it is also evident that the system would experience a slightly better damping performance for the base case (i.e. without any outages). It is also found that the system would experience the lowest small-disturbance angle stability margin for outage case 5. From the results given in Table 3, it is observed that slightly different power oscillation damping performance can be seen when the system is equipped with PVD control as compared to PFS. In contrast to the PFS control, the power change in the AC-DC system is different for PVD, which is reflected in power oscillation damping. However these differences are negligible.

Table 3: Impact on small-disturbance angle stability (heavy loading)

\begin{tabular}{|c|c|c|}
\hline Case & $\begin{array}{c}\text { \% damping with } \\
\text { PFS }\end{array}$ & $\begin{array}{c}\text { \% damping with } \\
\text { PVD }\end{array}$ \\
\hline Outage Case 1 & 2.86 & 2.83 \\
\hline Outage Case 2 & 2.90 & 2.90 \\
\hline Outage Case 3 & 2.92 & 2.89 \\
\hline Outage Case 4 & 2.70 & 2.68 \\
\hline Outage Case 5 & 2.60 & 2.58 \\
\hline Outage Case 6 & 2.72 & 2.70 \\
\hline Base Case & 3.33 & 3.33 \\
\hline
\end{tabular}

The small-disturbance analysis results for all nine considered operating conditions (shown in Table 2) are displayed in Fig. 6 against the base case. For ease of comparison, full detailed numerical results for all of the different considered cases are not included. Instead, the results present the range of critical interarea mode damping values seen across the range of operating cases considered. From the results given in Fig. 6, it can be observed that the DC grid reconfiguration has relatively minimal effects on the small-disturbance angle stability of the system. However, it is worth noting that the host AC system experiences a slightly lower smalldisturbance stability margin with reconfigured MTDC system as compared to the base case. It can also be seen that if the hierarchical controls (PFS and PVD) are neglected and the outages occur with no set point changes then slightly reduced stability is seen. 


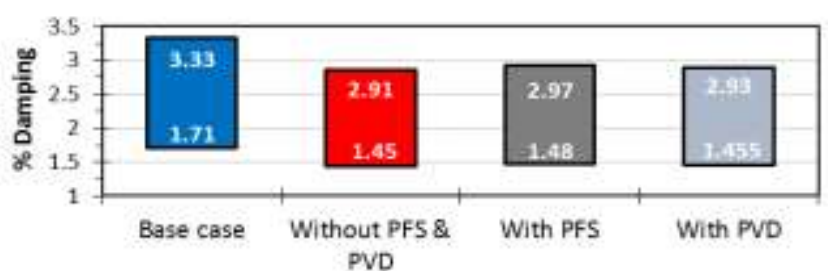

Fig. 6: Percentage damping for critical interarea mode.

Table 4 gives the results of large-disturbance angle stability margin of the AC system for MTDC grid reconfiguration scenarios given in Table 1, for both PFS and PVD control. It should be noted that as with all studies, it is assumed that the outage cases have occurred and the hierarchical controllers have acted, and the settings of the MTDC terminals are changed. Subsequently a disturbance is applied to the AC system to assess the transient stability performance of the AC system (i.e. the results do not refer to angle difference occurring following DC side faults). A standard disturbance of $100 \mathrm{~ms}$ self-clearing three-phase fault applied at bus 9 is used in all cases.

Primarily, under heavy loading condition, the system has a TSI value of 0.48 without an MTDC grid for the test disturbance. From the results given in Table 4, it is evident that the system experiences lower large-disturbance stability margin for various reconfigurations of MTDC grid. Note that the TSI can take a value from zero to one with lower values displaying greater angle separation and therefore an increased risk of transient instability. Furthermore, from the results, it is evident that the system experiences the lowest stability margin for case 2 with both PFS and PVD control. There are some differences between the TSI values when using the PFS control and the PVD control due to the difference in resulting power flow. However, the differences are minimal. From Table 4, it is also evident that the system experiences better large-disturbance stability margin for the base case (i.e. MTDC grid without outages).

Table 4: Impact on large-disturbance angle stability

\begin{tabular}{|c|c|c|}
\hline Case & TSI with PFS & TSI with PVD \\
\hline Outage Case 1 & 0.384 & 0.379 \\
\hline Outage Case 2 & 0.334 & 0.330 \\
\hline Outage Case 3 & 0.375 & 0.371 \\
\hline Outage Case 4 & 0.385 & 0.379 \\
\hline Outage Case 5 & 0.377 & 0.373 \\
\hline Outage Case 6 & 0.371 & 0.371 \\
\hline Base Case & 0.435 & 0.433 \\
\hline
\end{tabular}

The results recorded in Fig. 7 shows the range of TSI values for various operating conditions and faults (at a number of additional buses) in the host AC system. From the results given in Fig. 7, it is apparent that the host AC system experiences significantly lower large-disturbance angle stability margin with a reconfigured MTDC grid for both PFS and PVD control as compared to the system without an MTDC grid reconfiguration. The reconfiguration of MTDC grid changes the power flow pattern as well as the reactive power and AC voltage support available to the host AC system. Therefore, this results in the higher rotor angle deviation following the large-disturbance to the system. Furthermore, it is also observed that the system would experience a slightly lower large-disturbance stability margin without MTDC grid set point change by hierarchical control.

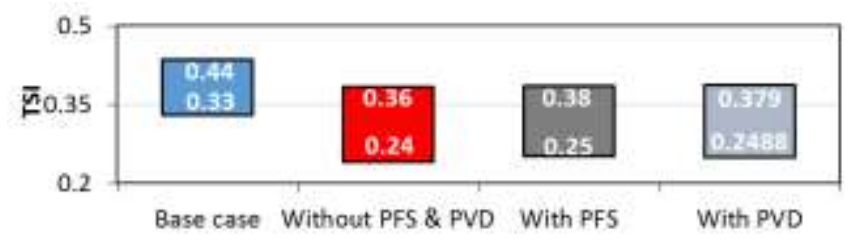

Fig. 7: Transient severity index (TSI) for various operating conditions.

\subsection{Impact on frequency stability}

Table 5 presents the RoCoF simulation results for underfrequency events. Different scenarios are considered for this analysis. However, the critical results that are for light to heavy loading conditions for outage 5 and the base case are presented here. A generator outage (1385 MW) at bus 4 is used to trigger an under-frequency event of the system. From the results in Table 5, it can be seen that the frequency stability margin of the representative GB system is reduced for outage 5 as compared to base case. From the results, it is evident that the system experiences the smallest frequency stability margin for the light loading condition due to the lower effective inertia in the system (generation in the North of Scotland is reduced for this case). From the results given in Table 5, it is evident that the various hierarchical controls in MTDC grid have minimal effect on the frequency dynamics of the system.

Table 5: RoCoF during the under-frequency event

\begin{tabular}{|c|c|c|c|c|}
\hline \multirow[t]{2}{*}{$\begin{array}{l}\text { Loading } \\
\text { condition }\end{array}$} & \multicolumn{2}{|c|}{$\begin{array}{c}\text { RoCoF Base Case } \\
(\mathrm{Hz} / \mathrm{s})\end{array}$} & \multicolumn{2}{|c|}{$\begin{array}{c}\text { RoCoF Outage } \\
\text { Case } 5(\mathrm{~Hz} / \mathrm{s})\end{array}$} \\
\hline & $\begin{array}{l}\text { With } \\
\text { PFS }\end{array}$ & $\begin{array}{l}\text { With } \\
\text { PVD }\end{array}$ & $\begin{array}{l}\text { With } \\
\text { PFS }\end{array}$ & $\begin{array}{l}\text { With } \\
\text { PVD }\end{array}$ \\
\hline Light loading & -0.543 & -0.542 & -0.782 & -0.784 \\
\hline $\begin{array}{l}\text { Medium } \\
\text { loading }\end{array}$ & -0.502 & -0.504 & -0.691 & -0.700 \\
\hline Heavy loading & -0.474 & -0.475 & -0.613 & -0.614 \\
\hline
\end{tabular}

The relative results for frequency stability of the system for outage case 5 are assessed and reported in Table 6 to illustrate the effect of set point on the system following a large frequency disturbance. The analysis has been conducted for the light loading condition for an outage of the generator at bus 4 . From the results given in Table 6 , it is evident that similar frequency responses can be achieved for outage 5 with and without set point change since the overall active power injection to the grid has not been altered for these scenarios. It is worth noting that the system experiences a lower frequency stability margin for outage 5 (both with and without set point change) with compared to the initial condition (i.e. base case).

\section{Conclusions}

An assessment of the impact of DC grid reconfiguration on the dynamic performance of the $\mathrm{AC}$ system is presented in 
this paper for PFS and DC pilot bus droop control. The dynamic behaviour of the AC-DC system is provided based on the typical GB transmission system and a five terminal offshore MTDC grid. From the analysis, it is evident that the impact of DC grid reconfiguration has minimal impacts on the small-disturbance rotor angle stability of the system since the small-disturbance angle stability is most significantly influenced by the operating conditions of the host AC system (i.e. number of conventional generators in operations, tie-line flow, operating condition near to the stability limit).

Table 6: Frequency response results

\begin{tabular}{|c|c|}
\hline Scenarios & $\operatorname{RoCoF}(\mathrm{Hz} / \mathrm{s})$ \\
\hline Base Case & -0.543 \\
\hline $\begin{array}{l}\text { Outage Case } 5 \text { without any } \\
\text { set point change }\end{array}$ & -0.792 \\
\hline $\begin{array}{c}\text { Outage Case } 5 \text { with set point } \\
\text { change by PFS }\end{array}$ & -0.782 \\
\hline $\begin{array}{c}\text { Outage Case } 5 \text { with set point } \\
\text { change by PVD }\end{array}$ & -0.784 \\
\hline
\end{tabular}

From the analysis, it is also evident that the effect of DC grid reconfiguration can be high for $\mathrm{AC}$ system large-disturbance angle and frequency stability due to the significant loss of infeed, reactive power support, and frequency support (if any). It is also found from the perspective of MTDC hierarchical controls that the DC power flow can be affected due to various hierarchical controls during the DC grid reconfiguration, thus leading to different $\mathrm{AC}$ system responses. However, from the perception of AC system dynamics, no real differences are seen for various hierarchical controllers (e.g. PFS and PVD). From the analysis, it should be worth noting that the host $\mathrm{AC}$ system would experience lower rotor angle stability margin for the DC system reconfiguration without any hierarchical controller.

The results presented in this paper are based on the primary control strategies of MTDC grid. The impact of other MTDC control strategies and frequency supplementary control through MTDC grid will be reported in future.

\section{Appendix}

DC line parameter: $R_{D C}=0.0113 \Omega / \mathrm{km} ; \quad L_{D C}=0.466$ $\mathrm{mH} / \mathrm{km}$; DC-side equivalent capacitance $=66 \mu \mathrm{F} ; \mathrm{DC}$ operating voltage $= \pm 500 \mathrm{kV}$; AC voltage $=521 \mathrm{kV}$; Power rating $=2000 \mathrm{MW}$.

\section{Acknowledgements}

This work was supported by the Engineering and Physical Sciences Research Council (EPSRC) funded project on Multi-terminal VSC-HVDC Networks: Grid Control (EP/ L021463/1) and Home Offshore (EP/P009743/1).

\section{References}

[1] T. M. Haileselassie, K. Uhlen, "Power system security in a meshed north sea HVDC grid," IEEE Proceedings, vol. 101, no. 4, pp. 978990, Apr. 2013.
[2] European Network for Transmission System Operators for Electricity (ENTSO-E), Ten year network development plan, Tech. Rep., ENTSOE, 2012.

[3] H. Rao, "Architecture of Nan'ao multi-terminal VSC-HVDC system and its multi-functional control," CSEE Journal of Power and Energy Systems, vol. 1, no. 1, pp. 9-18, Mar. 2015.

[4] D. Pudney, "Hierarchical control in a 5-terminal VSC-HVDC project," Energy Mag., Nov. 2014

[5] A. Egea-Alvarez, J. Beerten, D. V. Hertem, O. Gomis-Bellmunt, "Hierarchical power control of multi-terminal HVDC grids," Electrical Power System Research, vol. 121, pp. 207-215, 2015.

[6] M. Barnes, D. Van Hertem, S. P. Teeuwsen, and M. Callavik, "HVDC system in smart grids," Proceedings of the IEEE, vol. 105, no. 11, pp. 2082-2098, Nov. 2017

[7] N. R. Chaudhuri, R. Majumder, B. Chaudhuri, and J. Pan, "Stability analysis of VSC MTDC grid connected to multimachine AC systems," IEEE Trans. Power Delivery, vol. 26, no. 4, pp. 2774-2784, Oct. 2011.

[8] N. R. Chaudhuri, B. Chaudhuri, "Adaptive droop control for effective power sharing in multi-terminal DC (MTDC) grids," IEEE Trans. Power Systems, vol. 28, no. 1, pp. 21-29, Feb. 2013

[9] F. B. Ajaei, R. Iravani, "Dynamic interactions of the MMC-HVDC grid and its host AC system due to AC-side disturbances," IEEE Trans. Power Delivery, vol. 31, no. 3, pp. 1289-1298, Jun. 2016.

[10] L. Shen, M. Barnes, R. Preece, J. V. Milanovic, K. R. W. Bell, and M. Belivanis, "The effect of VSC HVDC control on AC system electromechanical oscillations and DC system dynamics," IEEE Trans. Power Delivery, vol. 31, no. 3, pp. 1085-1095, Jun. 2016.

[11] Cigré Working Group, "Guide for the development of models for HVDC converters in a HVDC grid," Tech. Brochure 604, Paris, France, Dec. 2014.

[12] K. Rouzbehi, A. Miranian, J. I. Candela, A. Luna, and P. Rodriguez, "A hierarchical control structure for multi terminal VSC-based HVDC grids with GVD characteristics," in International Conference on Renewable Energy Research and Applications, 2013.

[13] K. Rouzbehi, A. Miranian, A. Luna, and P. Rodriguez, "DC voltage control and power sharing in multi-terminal DC grids based on optimal power flow and voltage-droop," IEEE Journal of Emerging and Selected Topics in Power Electronics, vol. 2, no. 4, pp. 1171-1179, Dec. 2014

[14] A. Beddard, A. Adamczyk, M. Barnes, and C. Barker, "HVDC grid control system based on autonomous converter control," in $8^{\text {th }}$ IET International Conference on Power Electronics, Machines and Drives (PEMD 2016), 2016

[15] L. Shen, W. Wang, and M. Barnes, "The influence of MTDC control on DC power flow and AC system dynamic responses," in IEEE Power and Energy Society General Meeting (PESGM 2014), 2014.

[16] M. Abedrabbo, M. Wang, P. Tielens, F. Z. Dejene, W. Leterme, J Beerten, and D. Van Hertem, "Impact of DC grid contingencies on AC system stability," in $13^{\text {th }}$ IET International Conference on AC and DC Transmission (AC DC 2017), 2017.

[17] F. Thams, R. Eriksson, and M. Molinas, "Interaction of droop control structures and its inherent effect on the power transfer limits in multiterminal VSC-HVDC," IEEE Trans. Power Delivery, vol. 32, no. 1, pp. 182-192, Feb. 2017

[18] A. Kirakosyan, E. F. El-Saadany, M. S. El Moursi, and K. Al Hosani, "DC voltage regulation and frequency support in pilot voltage droop controlled multi-terminal HVDC systems," IEEE Trans. Power Delivery (Early Access), 2017.

[19] R. T. Pinto, M. Aragues, O. Gomis-Bellmunt, A. Sumper, and P. Bauer, "Analysis of deviations on the optimal power flow operation of MTDC networks: A comparison between droop control and DVC strategy," in $17^{\text {th }}$ European Conference on Power Electronics and Applications, 2015.

[20] DIgSILENTGmbH, "DIgSILENT Power Factory V 17.0 -User Manual," DIgSILENTGmbH, 2017.

[21] R. Shah, M. Barnes, and R. Preece, "Offshore AC grid management for an AC integrated VSC-HVDC scheme with large WPPs," in IEEE Power and Energy Society General Meeting (PESGM), 2016.

[22] PPA Energy. Rate Of Change Of Frequency (ROCOF) Final Report 2013. [Online]. Available: http://www.cer.ie/docs/000260/cer13143. 